\title{
Performance of microbial fuel cells operated under anoxic
}

\section{conditions}

Stanislaw Marks ${ }^{1}$, Jacek Makinia ${ }^{2}$ and Francisco Jesus Fernandez-Morales ${ }^{3, *}$

1 Poznań University of Life Sciences. Institute of Biosystems Engineering, ul.

Wojska Polskiego 50, 60-637 Poznań, Poland.

2 Technical University of Gdansk, Department of Environmental Engineering, ul. Narutowicza 11/12, 80-952, Gdansk, Poland.

3 University of Castilla-La Mancha, Faculty of Chemical Sciences \& Technologies, Chemical Engineering Department, Avenida Camilo José Cela, 12. 13071 Ciudad Real, Spain.

* Corresponding author: Francisco Jesús Fernández Morales

University of Castilla-La Mancha, ITQUIMA, Chemical Engineering Dept., Avda. Camilo José Cela S/N 13071, Ciudad Real, Spain.

Tel: 0034926295300 (ext. 6350), Fax: 0034926295242.

E-mail: $\underline{\text { fcojesus.fmorales@uclm.es }}$

Orcid iD: 0000-0003-0389-6247 


\section{Abstract}

Nowadays, microbial fuel cells (MFC) stand up as a promising renewable energy source. Due to the ability of the MFC to oxidize a wide spectrum of substrates, wastewater seems to be one of the most interesting fuels. Unfortunately, wastewater could contain electron acceptors such as nitrate, which could interfere with the electrical performance of the MFC. In this work, the influence of oxidised nitrogen forms on the electricity production of an air breathing MFC was studied. It was observed that power generation was not significantly influenced when operated at nitrate concentrations below $0.9 \mathrm{mg} \mathrm{N}-\mathrm{NO}_{3} \mathrm{~L}^{-1}$. However, when the nitrate concentrations were above this value, the electricity generation was reduced. In order to investigate the causes of this reduction, an electrochemical characterization of the MFC was performed. The results of polarization curves were fitted to an empirical mathematical model. From the results it was observed that, when nitrate was present, the denitrifiers outcompeted the electrogenic microorganisms for substrate, causing mass transfer limitations to the electrogenic process.

Keywords: Microbial fuel cell; nitrate; electrochemical performance; modelling 


\section{Introduction}

Microbiological fuel cells (MFCs) are bioelectrochemical systems capable of generating electricity from oxidation of chemical substrates by so-called electrogenic microorganisms [1]. The oxidation process takes place in the anode of the MFC whereas the exerted electrons are externally conduced to a cathode, where he electrons are utilized in a reduction reaction[2]. In this way, the oxidation/reduction reactions generate an electrical current [3]. It should be emphasized that the electrogenic microorganisms powering MFCs can oxidize a wide spectrum of chemical compounds present in municipal wastewater [4]. Many of those compounds are readily biodegradable and therefore very conveniently used as fuel in a MFC. Because of that property, municipal wastewater is nowadays considered as one of the best energy sources for MFCs.

By using the MFC systems, the chemical energy stored in wastewater can be directly converted into electricity by turning simultaneously the conventional energy consuming treatment processes into energy-yielding ones [5]. Moreover, when treating wastewater by means of MFCs, operational energy savings can additionally be obtained. On one hand, the aeration stage, which accounts for approximately $50 \%$ of the plant operational costs, becomes no longer needed [6]. On the other hand, the MFC process behaves as an anaerobic process, presenting low specific growth rates and therefore reducing the amounts of generated solids, which alleviates the solids handling costs [2].

The conventional wastewater treatment processes consume approximately $0.5-2 \mathrm{kWh} / \mathrm{m}^{3}$ depending on the required treatment efficiency and wastewater characteristics [7]. In general, wastewater contains a very high amount of energy, mainly as chemical energy [7], which can be successfully extracted as electricity by means of MFCs. This chemical energy contained is mainly presented as organic chemicals $\left(\sim 1.79 \mathrm{kWh} / \mathrm{m}^{3}\right)$ and inorganic chemicals $(\sim 0.7$ $\mathrm{kWh} / \mathrm{m}^{3}$ ) [5]. Unfortunately, the wastewater sometimes contains high concentrations of oxidizing agents, such as nitrate, etc. These chemicals could compete with the solid electrode 
as an electron acceptor reducing the energy recovery yields [8]. When the electrogenic culture of a MFC use other electron acceptors instead of the anode, the energy exerted by the MFC could be reduced or even stopped. These problems could be avoided by operating a pure culture MFC incapable of denitrification. However, few monoculture strains have the capacity to produce power densities as great as strains that are inoculated in mixed communities [9]. In the mixed cultures, consortia of microorganisms grow competing for the same substrates [10]. This competition leads to the survival of the most appropriate microorganisms [11]. The operation with mixed cultures is very convenient, not only because of the higher power exerted, but also because of its lower operational costs and the possibility of dealing with wastewater as fuel [12].

Unfortunately, the influence of the oxidants, such as nitrate, on the performance of a MFC remains unclear. The electrical performance of MFCs under anoxic conditions has been previously described by [13] who observed that the presence of nitrate modified the microbial population in the long-term perspective. In contrast, Lian et al. [14] did not observe any change in the anodic microbial population. Sukkasem et al. [15] found that the Coulombic Efficiency (CE) was influenced by the oxidised nitrogen, whereas the maximum voltage output remained unaffected. However, an opposite behaviour was observed by Yi and Harper [16] and by Kashima and Regan [17]. Because of the ambiguous results, more research is required to deepen the knowledge on the effects of nitrate on the MFC performance. This feature is of particular interest since many electrogenic microorganisms, such as Geobacter [17] and Shewanella spp. [18], harbor nitrate reduction capabilities. The identification of the driving force of the performance reduction of the MFC may point out the main flaws in the electrochemical process, which would be a very useful information for practitioners planning the application of a MFC for wastewater treatment or environmental remediation coupled with energy generation. 
In this context, the aim of this study was to determine whether the presence of nitrate interferes with the energy generation in an MFC and to explain how the bio-electrochemical process is affected by the presence of nitrate. 


\section{Materials and Methods}

\subsection{Experimental set-up}

The MFC used in this study was a two compartment device made of graphite plates. Graphite plates have presented excellent characteristics for MFC manufacture [19]. Anodic and cathodic compartments were separated by a commercial membrane Sterion ${ }^{\circ}$. During the experiments, the anode and the cathode were externally connected by means of a resistance of $125 \Omega$. A low resistance load was selected to enable the growth of the electrogenic microbial culture in the MFC [20]. The anodic chamber had a volume of $0.95 \mathrm{~cm}^{3}$, and the active area of the anodic electrode was $4.65 \mathrm{~cm}^{2}$. The cathodic chamber had a volume of $0.50 \mathrm{~cm}^{3}$, and the active area of the cathodic electrode was $2.85 \mathrm{~cm}^{2}$. Both electrodes were made of Toray carbon paper TGPH-120 (E-Tek, U.S.A.). The mechanical properties of the electrodes were enhanced by adding a Teflon content of $20 \%$ in the case of the anode and $10 \%$ in the case of the cathode. The MFC was constructed by using a membrane-electrode assembly [21]. In this way, the gap between the electrodes and the internal resistance were minimized.

The cathode used in the MFC was based on the air-breathing system, in which free convection of airflow supplies oxygen to the cathode. These systems are robust as described by [22]. The catalytic properties of the cathode were enhanced by adding a catalytic layer of $0.5 \mathrm{mg} \mathrm{Pt} / \mathrm{cm}^{2}$. More information about the MFC used in this study can be found elsewhere [22].

A schematic diagram of the experimental set-up is presented in Figure 1. 


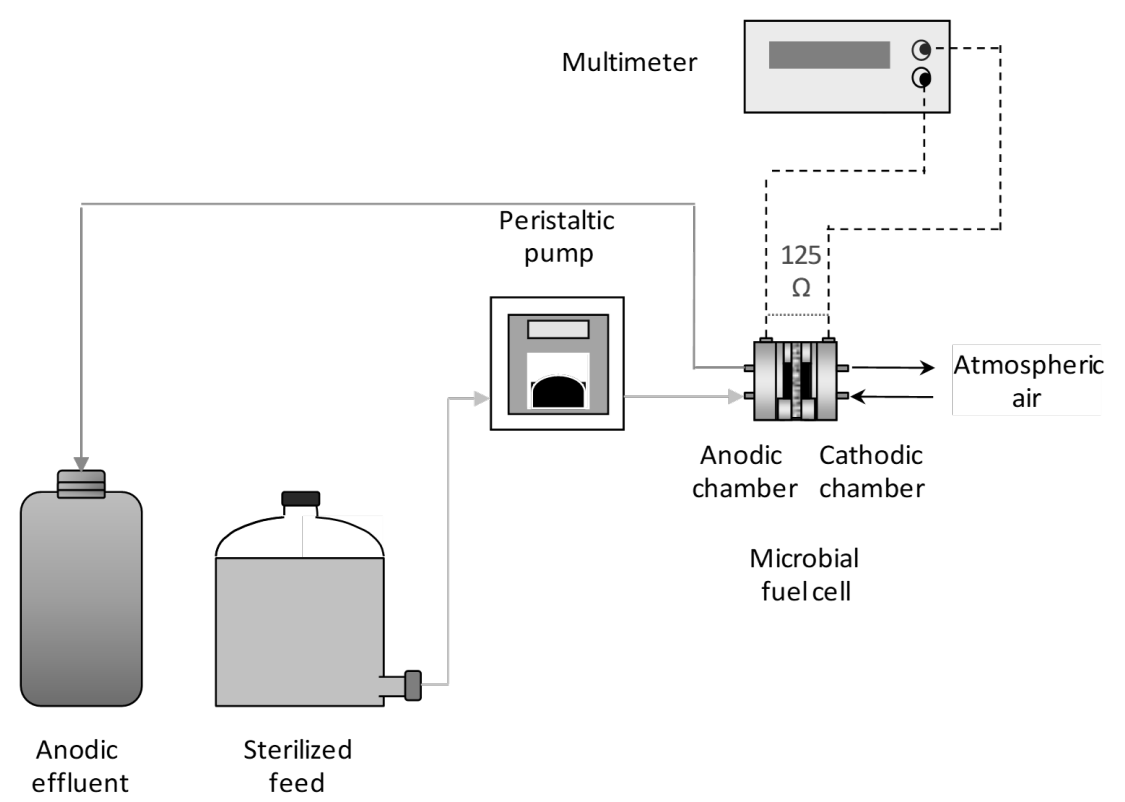

Figure 1. Lay-out of the experimental set-up.

The MFC was operated during two days before the inoculation with a Geobacter enriched mixed culture withdrawn from the effluent of a working MFC [23]. Operating in this way, the absence of electricity generation served as abiotic control before the inoculation. The anodic chamber of the MFC was continuously fed with synthetic wastewater from a reservoir with the working volume of $250 \mathrm{~mL}$ at the flow rate of $0.2 \mathrm{~mL} \mathrm{~min}^{-1}$. To avoid degradation of the

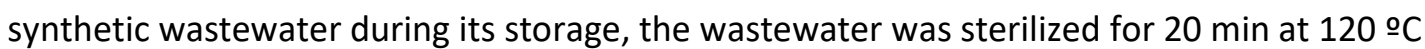
[24]. The synthetic wastewater was composed of: glucose $161 \mathrm{mg} \mathrm{L}^{-1}$, fructose $161 \mathrm{mg} \mathrm{L}^{-1}$, $\mathrm{NaHCO}_{3} 111 \mathrm{mg} \mathrm{L}^{-1},\left(\mathrm{NH}_{4}\right)_{2} \mathrm{SO}_{4} 74,2 \mathrm{mg} \mathrm{L}^{-1}, \mathrm{KH}_{2} \mathrm{PO}_{4} 44.5 \mathrm{mg} \mathrm{L}^{-1}, \mathrm{MgCl}_{2} 37.1 \mathrm{mg} \mathrm{L}^{-1}, \mathrm{CaCl}_{2} 30.7 \mathrm{mg}$ $\mathrm{L}^{-1}$ and $\left(\mathrm{NH}_{4}\right)_{2} \mathrm{Fe}\left(\mathrm{SO}_{4}\right)_{2} 3.1 \mathrm{mg} \mathrm{L}^{-1}$.

In order to study short-term effects of nitrate on the MFC performance, nitrate was periodically dosed to the synthetic wastewater. The nitrate concentrations studied ranged from 0 to $3.4 \mathrm{mg} \mathrm{N}-\mathrm{NO}_{3} \mathrm{~L}^{-1}$. These doses were maintained during 10 hours and the effect on the MFC performance was studied in terms of electricity generation and COD, nitrate and nitrite removal efficiency. The experiments were carried out in duplicate. 


\subsection{Characterization Techniques}

The Chemical Oxygen Demand (COD), nitrate nitrogen $\left({\mathrm{N}-\mathrm{NO}_{3}}^{-}\right)$and nitrite nitrogen $\left(\mathrm{N}-\mathrm{NO}_{2}{ }^{-}\right)$ concentrations were measured according to the Standard Methods [25]. The oxidized nitrogen removal was determined by measuring nitrate and nitrite nitrogen forms. The corrected value for the oxidised nitrogen removal, i.e. nitrite and nitrate, was determined by using the following equation proposed by [26]:

$$
\Delta_{N-\text { corrected }}=\left(\Delta_{N-N O_{3}}-0.6 \cdot \Delta_{N-N O_{2}}\right)
$$

The voltage generated was measured using a high-impedance electrometer Keithley 2000, Tektronix Company, United States of America. Polarization curves were recorded using an Autolab PGSTAT 30 potentiostat/galvanostat, (Ecochemie Company, The Netherlands) at a scan rate of $0.001 \mathrm{~V} \mathrm{s-1}$. Polarization curves provide important information about the electrochemical performance of the MFC. The polarization curves allow to evaluate three important parameters of the MFC operation, including the open circuit voltage (OCV) or the maximum allowable MFC voltage (for a nil current), the maximum intensity reachable (for a nil potential) and the maximum feasible power density. In addition, the shape of the curve provides information about the limiting stage controlling the performance of the cell, which is very important to identify the problems with the aim to tackle them. 


\section{Results}

\subsection{Microbial Fuel Cell Performance}

In order to evaluate the maximum electricity generation in the MFC used in this study, the setup was operated during four weeks under strict anaerobic conditions. Once reached the steady-state, the voltage exerted was $6.3 \pm 0.1 \mathrm{mV}$. Subsequently, different nitrate concentrations were added to the influent wastewater fed to the MFC. In order to evaluate a possible hysteresis in the behaviour of the MFC, the nitrate concentrations were first stepwise increased and then stepwise decreased [27]. During these tests, the exerted voltage was determined by means of a high impedance multimeter. Samples were taken from the liquid bulk to follow the nitrate and nitrite trends in the course of the tests. Figure 2 presents the exerted voltage in terms of the nitrate concentrations fed to the MFC.

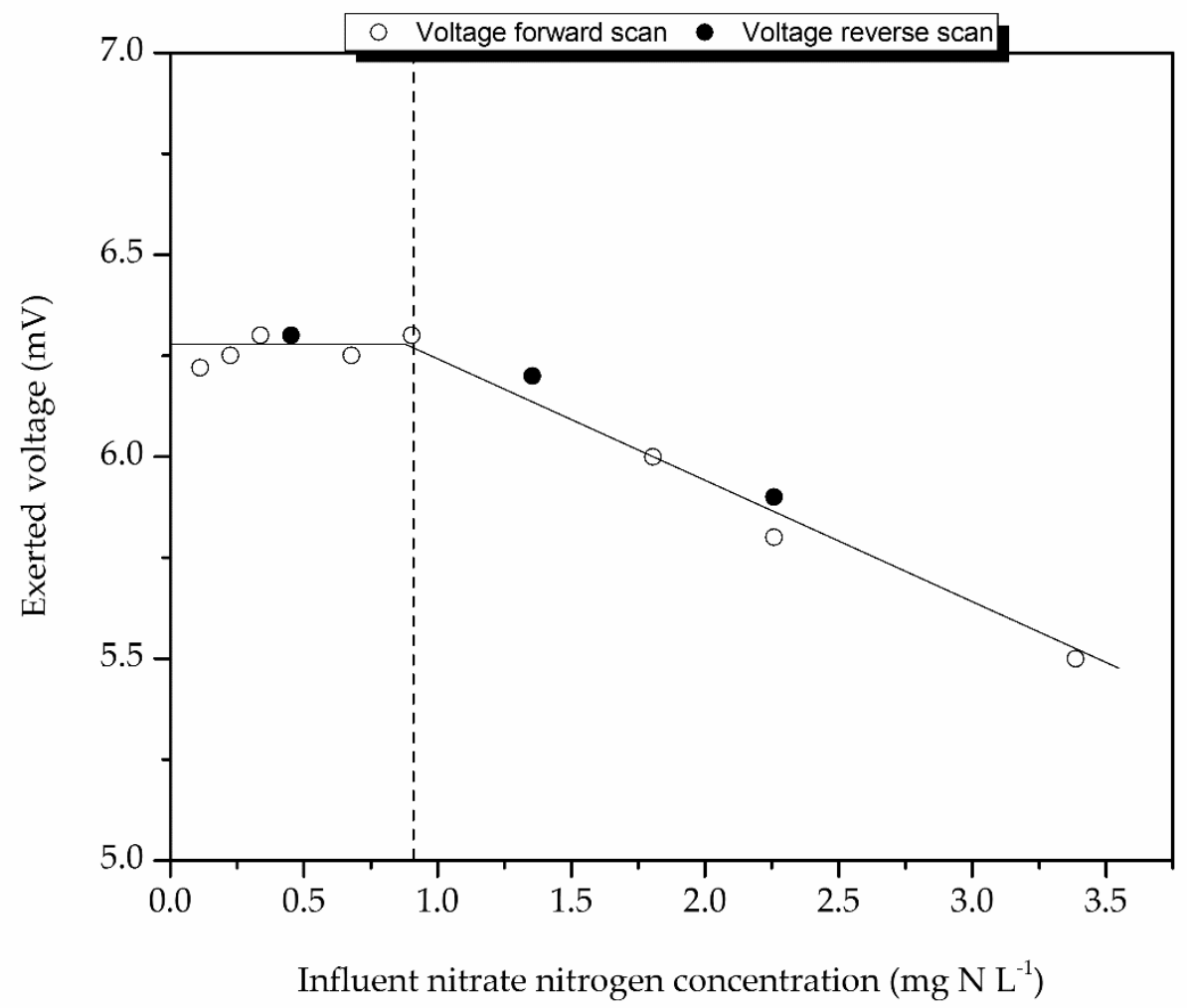

Figure 2. Influence of the nitrate on the voltage of the MFC. 
The obtained results indicated that the system did not present hysteresis. In Figure 2, it can be seen that the exerted voltage were the same in both forward and reverse scan for the same influent nitrate concentrations.

With regard to the effect of nitrate on the electricity generation of the system, two different behaviours were observed. On one hand, nitrate concentrations up to $0.9 \mathrm{mg} \mathrm{N}-\mathrm{NO}_{3} \mathrm{~L}^{-1}$ did not reduce the exerted voltage. This behaviour could be explained by an imperceptible influence of the low nitrate concentrations on the performance of the electrogenic microorganisms in the MFC. However, on the other hand, concentrations higher than $0.9 \mathrm{mg} \mathrm{N}-\mathrm{NO}_{3} \mathrm{~L}^{-1}$ negatively affected the voltage exerted by the MFC. This effect could be justified by at least two hypotheses presented in the literature:

- The competition for the substrate between the electrogenic microoganisms and denitrifiers [28].

- Inhibitory effects of nitrate on the behaviour of the electrogenic microorganisms [16].

In order to investigate the causes leading to reduction in the voltage exerted, the effluent nitrate and nitrite concentrations were measured (Figure 3). 


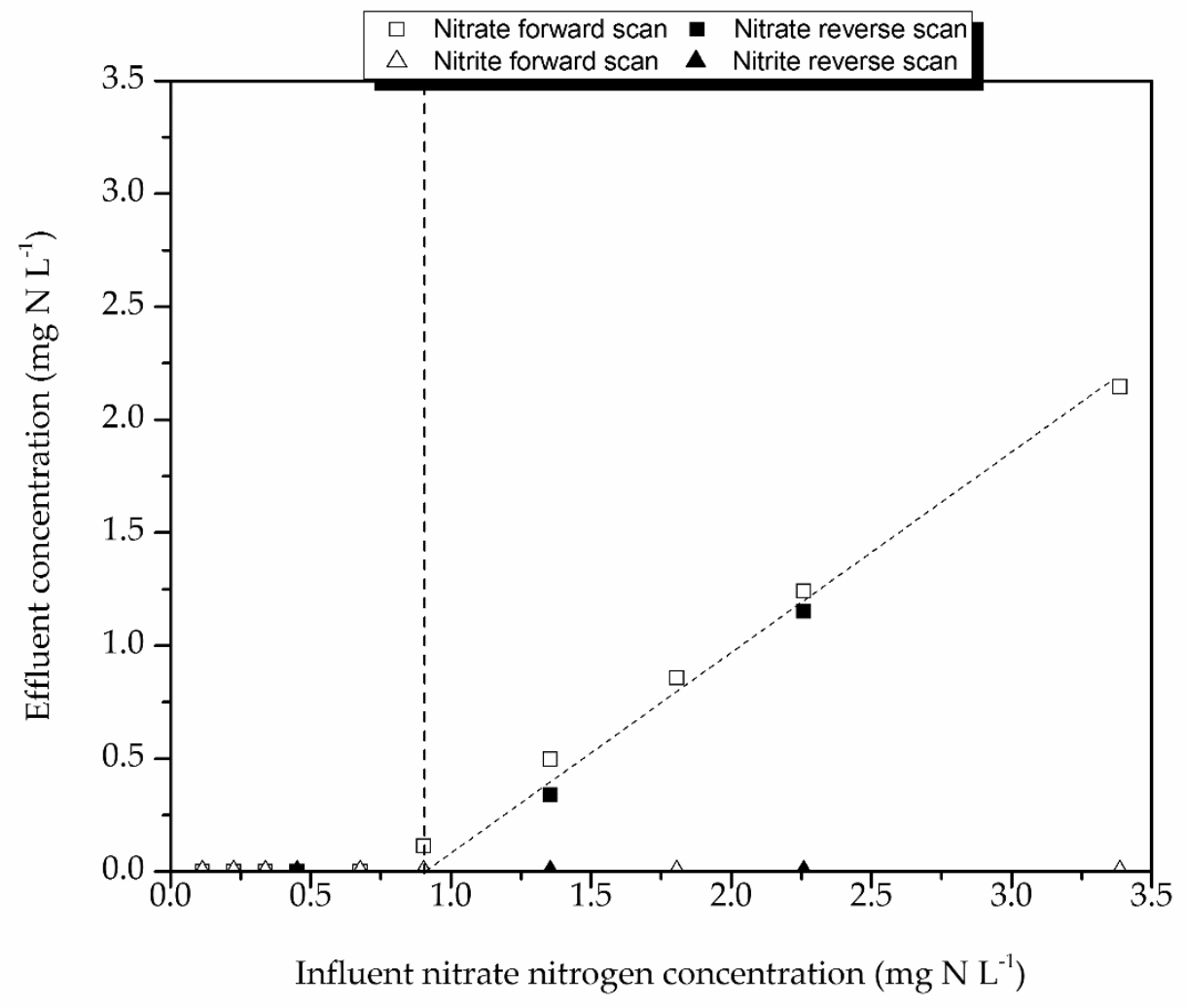

Figure 3. Relationship between the influent nitrate concentration and the effluent oxidised nitrogen, nitrite and nitrate, concentrations.

As can be seen in Figure 3, no hysteresis was observed in the effluent nitrite and nitrate concentrations. Figure 3 also shows that nitrate was completely removed when the MFC

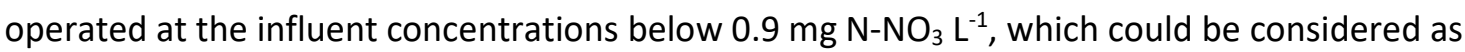
nearly anaerobic operational conditions. Under these conditions, no interference in the voltage generation was observed. However, when the influent nitrate concentration fed to the anodic chamber exceeded $0.9 \mathrm{mg} \mathrm{N}-\mathrm{NO}_{3} \mathrm{~L}^{-1}$ it was not fully consumed and anoxic conditions were maintained. These anoxic conditions ensured the full availability of nitrate which significantly influenced the voltage exerted by the MFC. The effect of nitrate can be quantified as a linear reduction of approximately $0.4 \mathrm{mV}$ per $\mathrm{mg} \mathrm{N}-\mathrm{NO}_{3} \mathrm{~L}^{-1}$ fed to the MFC. With regard to the nitrate removal by the MFC microbial culture, the maximum nitrate removal rate was 
obtained when feeding nitrate concentrations above $2.3 \mathrm{mg} \mathrm{N}-\mathrm{NO}_{3} \mathrm{~L}^{-1}$, being the maximum nitrate removal rate of $55 \mathrm{mg} \mathrm{N}-\mathrm{NO}^{3-} \mathrm{L}^{-1} \mathrm{~h}^{-1}$. Similar denitrification rates have been described in the literature when operating with denitrifying activated sludge [29].

In the case of nitrite, it can be seen in Figure 3 that its concentration was negligible regardless of the influent nitrate concentrations fed to the MFC. The complete nitrite removal can be explained because it is the non-limiting stage of the denitrification process. The high nitrite removal rate was verified by performing a test in which wastewater, supplemented with a nitrite dose of $1.2 \mathrm{mg} \mathrm{N}-\mathrm{NO}_{2} \mathrm{~L}^{-1}$, was fed to the MFC and the nitrite concentration was monitored along with the exerted voltage. It was observed that almost any interference in the electricity production took place (data not shown). This can be explained by the very high nitrite removal rate, which does not interfere with the voltage exerted. Therefore, the effect of the nitrite on the voltage exerted by the MFC was negligible.

During the experiments the $\mathrm{pH}$ evolution was measured and no significant changes were observed. This can be explained by the absence of acidogenic fermenters in the mixed microbial culture used in this work [30].

In order to investigate the effect of nitrate on the performance of the MFC, COD removal was studied to identify whether inhibitory or competitive effects took place between denitrification and the electrogenic processes. The total COD removal was measured in terms of the influent nitrate concentration and the COD removal rate due to denitrification was determined using the following mass balance equation (Eq. 2) [26]:

$$
\frac{d S_{D Q O}}{d t}=\frac{2,86}{1-Y_{M}} \cdot \frac{d S_{N-N O_{3}}}{d t}
$$

Figure 4 presents the total COD consumption as well the COD consumption caused by the denitrification process. 


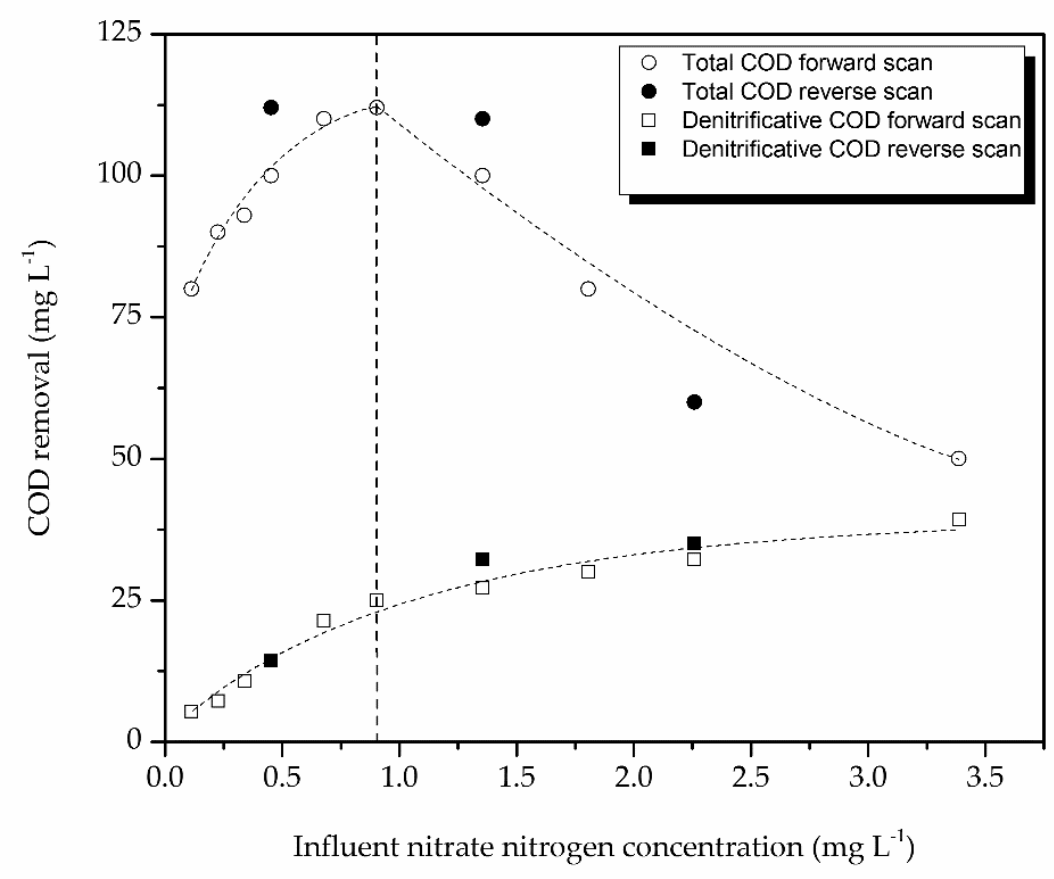

Figure 4. Effect of the influent nitrate concentration on COD removal.

In Figure 4, it can be seen that the removal of COD was affected by the presence of nitrate.

Initially, the total COD removed increased with the increasing influent nitrate concentration.

The explanation is the contribution of denitrification process on the COD removal. When

working with nitrate concentrations over $0.9 \mathrm{mg} \mathrm{N}-\mathrm{NO}^{3-} \mathrm{L}^{-1}$, the trend of the total COD removal changed to a decreasing one, in spite of the higher COD removal expected due to the higher extension of the denitrification process. This result could be explained by the two hypotheses previously exposed, including the competence and/or inhibition. With the aim to identify the practical effects of nitrate on the MFC performance, an electrochemical characterization of the system was carried out.

\subsection{Electrochemical characterization}

The electrochemical characterization was based on polarization curves and power curves of the MFC when the MFC was operated at the different influent nitrate concentrations. The 
results are graphically shown in Figure 5 and Figure 6 , and the main parameters obtained from these polarization curves are summarized in Table 1.

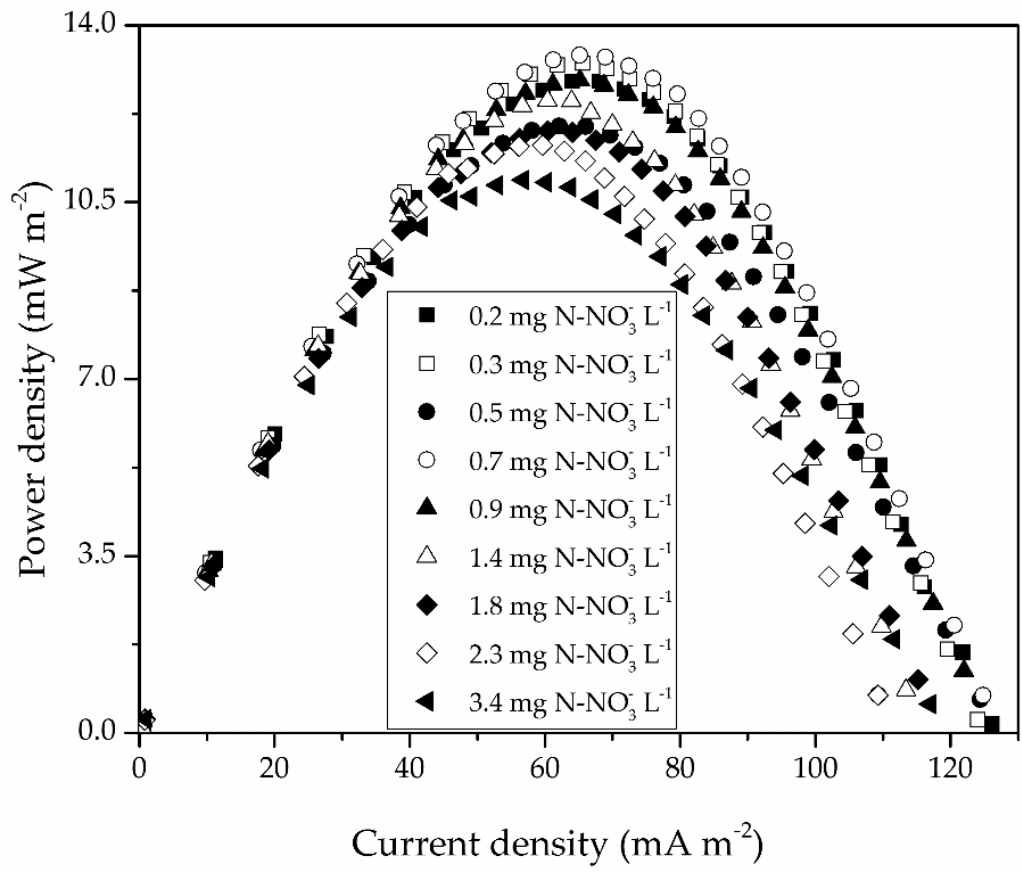

Figure 5. Power curves under different influent nitrate nitrogen concentrations.

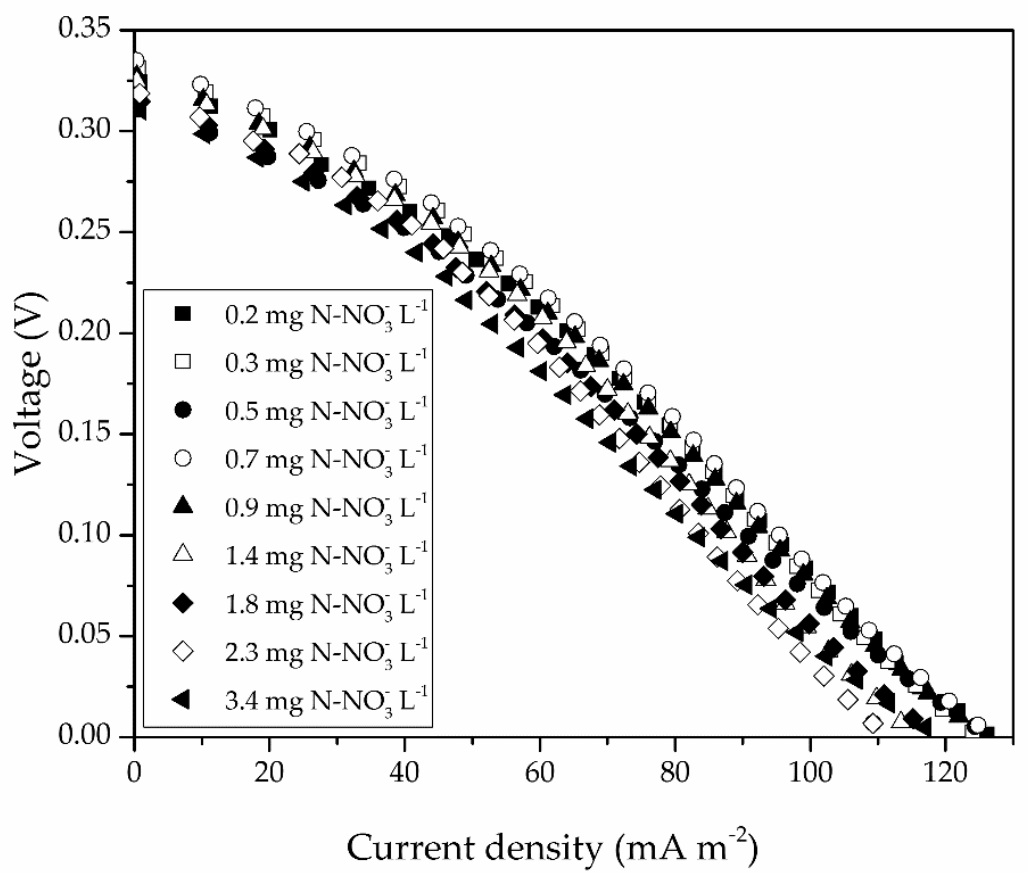

Figure 6. Polarization curves under different influent nitrate nitrogen concentrations. 
Table 1. Stationary values of the main electrical parameters of the MFCs in terms of the influent nitrate concentrations.

\begin{tabular}{|c|c|c|c|}
\hline 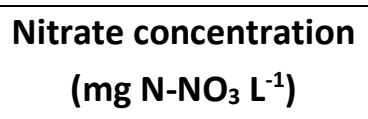 & OCV $(m V)$ & $\begin{array}{c}P_{\max } \\
\left(m W \mathrm{~m}^{-2}\right)\end{array}$ & $\begin{array}{c}j_{\max } \\
\left(\mathrm{mA} \mathrm{m}^{-2}\right)\end{array}$ \\
\hline 0.0 & 340.0 & 13.8 & 70 \\
\hline 0.2 & 324.7 & 13.5 & 69 \\
\hline 0.3 & 331.1 & 13.2 & 68 \\
\hline 0.5 & 324.1 & 13.0 & 66 \\
\hline 0.7 & 334.9 & 12.9 & 66 \\
\hline 0.9 & 327.3 & 12.4 & 64 \\
\hline 1.4 & 318.6 & 12.4 & 63 \\
\hline 1.8 & 314.6 & 11.8 & 62 \\
\hline 2.3 & 310.8 & 11.5 & 55 \\
\hline 3.4 & 310.4 & 10.8 & 55 \\
\hline
\end{tabular}

The analysis of the power curves indicate that the MFC operated under strict anaerobic conditions, with no nitrate addition, yielded the best performance, reaching the OCV of 0.340 $\mathrm{V}$, the maximum current density of approximately $13 \mathrm{~mA} \mathrm{~m}^{-2}$, and the maximum power density of $70 \mathrm{~mW} \mathrm{~m}^{-2}$. All these values slightly decreased when low nitrate concentrations were fed to the MFC, but the most significant reduction was observed when the nitrate nitrogen concentration fed to the MFC exceeded $0.9 \mathrm{mg} \mathrm{N}-\mathrm{NO}_{3} \mathrm{~L}^{-1}$. Under these conditions, the OCV steeply decreased. The value of OCV reached about $310 \mathrm{mV}$ which was $9 \%$ lower than that obtained when no nitrate was fed to the system. With regard to the maximum power and current density exerted, they also decreased gradually reaching the ultimate values of about $10.8 \mathrm{~mW} \mathrm{~m}^{-2}$ and $55 \mathrm{~mA} \mathrm{~m}^{-2}$, respectively. Those values are about $22 \%$ lower than those obtained when operated without nitrate addition.

The reduction trends were fitted to linear equations. The exerted voltage decreased about 9.3 $(\mathrm{mV})\left(\mathrm{mg} \mathrm{N}^{-N \mathrm{O}_{3}} \mathrm{~L}^{-1}\right)^{-1}\left(\mathrm{r}^{2}=0.93\right)$. The maximum current density decreased about $0.85\left(\mathrm{~mA} \mathrm{~m}{ }^{2}\right)$ ( $\left.m g ~ N-N_{3} \mathrm{~L}^{-1}\right)^{-1}\left(\mathrm{r}^{2}=0.96\right)$ and the maximum power density decreased about $\left.4.25 \mathrm{~mW} \mathrm{~m}{ }^{2}\right)(\mathrm{mg}$ $\left.\mathrm{N}-\mathrm{NO}_{3} \mathrm{~L}^{-1}\right)^{-1}\left(\mathrm{r}^{2}=0.90\right)$. Because of the good fitting observed, the performance reduction can be explained by a linear trend. 


\subsection{Polarization curves fitting}

In the literature numerical approach have been used for MFC analysis [31]. In this work, in order to isolate the mechanisms controlling the worst performance of the MFC when it was subjected to nitrate loads, the results of the polarization curves were fitted to a mathematical model proposed by [32].

$E_{\text {cell }}=E_{0}-b \cdot \log (i)-R \cdot i-m \cdot \exp (n i)$

In this equation, the voltage exerted by the MFC is calculated by subtracting the losses caused by activation $(-b \cdot \log (i))$, ohmic resistance $(-R \cdot i)$, and mass transfer limitations $(-m \cdot \exp (n i))$ from the maximum achievable potential, which is the standard potential $\left(E_{0}\right)$. Results of modelling are summarized in Table 2 and graphically shown in Figure 7. In this figure, only two concentrations are presented for the sake of clarity and accurate fitting $\left(r^{2}>\right.$ 0.94) can be seen.

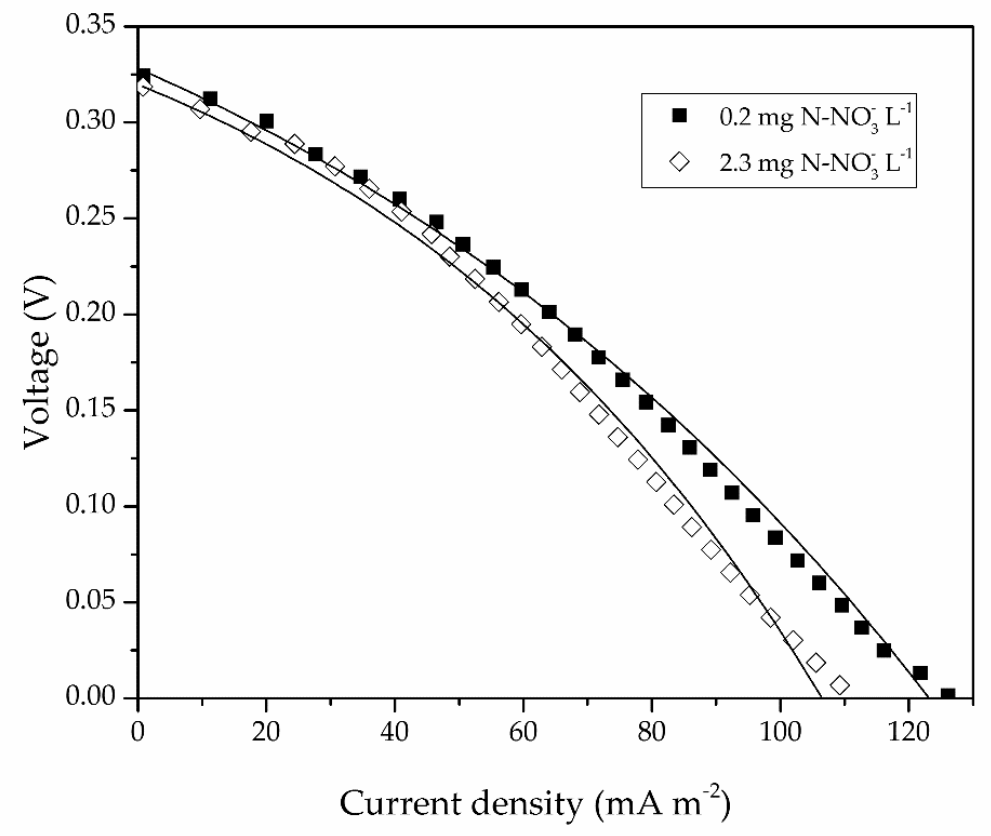

Figure 7. Fitting results of the polarization curves obtained for the influent nitrate concentrations of 0.2 and $2.3 \mathrm{mg} \mathrm{N}-\mathrm{NO}_{3} \mathrm{~L}^{-1}$. 
Table 2. Parameters values obtained in modelling the polarization curves.

\begin{tabular}{|c|c|c|c|c|c|c|}
\hline \multirow[b]{2}{*}{ 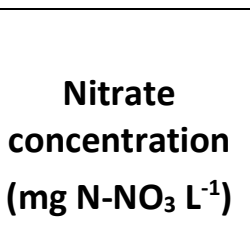 } & \multicolumn{6}{|c|}{ Parameter } \\
\hline & $E_{0}(V)$ & $\begin{array}{c}B \\
\left(\text { V decades }^{-1}\right)\end{array}$ & $\begin{array}{l}R_{i} \\
(\Omega)\end{array}$ & $\begin{array}{l}m \\
(V)\end{array}$ & $\begin{array}{c}n \\
\left(m A^{-1}\right)\end{array}$ & $\begin{array}{c}\text { Correlation } \\
\text { coefficient } \\
R^{2}\end{array}$ \\
\hline 0.0 & 0.3306 & 0.005 & 811.3 & 0.030 & 45000.0 & 0.9438 \\
\hline 0.2 & 0.3247 & 0.005 & 811.3 & 0.030 & 33202.3 & 0.9919 \\
\hline 0.3 & 0.3311 & 0.005 & 811.3 & 0.030 & 31451.8 & 0.9747 \\
\hline 0.5 & 0.3241 & 0.005 & 811.3 & 0.030 & 34824.5 & 0.9732 \\
\hline 0.7 & 0.3349 & 0.005 & 811.3 & 0.030 & 31241.3 & 0.9777 \\
\hline 0.9 & 0.3273 & 0.005 & 811.3 & 0.030 & 31241.3 & 0.9715 \\
\hline 1.4 & 0.3186 & 0.005 & 811.3 & 0.030 & 30034.9 & 0.9800 \\
\hline 1.8 & 0.3146 & 0.005 & 811.3 & 0.030 & 32130.5 & 0.9757 \\
\hline 2.3 & 0.3108 & 0.005 & 811.3 & 0.030 & 30068.4 & 0.9939 \\
\hline 3.4 & 0.3104 & 0.005 & 811.3 & 0.030 & 32589.8 & 0.9450 \\
\hline
\end{tabular}

The obtained results showed that the $E_{0}$ values were nearly the same when dosing nitrate, this behaviour indicates a negligible influence of nitrate on the standard voltage. With regard to the activation losses, all the experimental data sets were fitted with the same $b$ value of 0.005 $V$ decades $^{-1}$ indicating negligible effects of the nitrate over the electrocatalytic activity. This $b$ value is a typical value presented in the literature when fitting polarizations curves [32]. With regard to the internal resistance value, $R$ value, when the MFC was operated under different nitrate concentrations, the same value was obtained in all the cases. This result indicated that hardly any effect of the nitrate concentration was observed on the internal resistance. Finally the mass transfer limitations was studied. The fitting values of the parameter $m$ was the same in all the cases (Table 2). The parameter $m$ is linked to the importance of the mass transfer phenomena when the threshold current density was exceeded. This result indicates that the proportional effects on the performance were expected. With regards to the $n$ parameter, it should be emphasized that the value obtained from modelling was variable. The $n$ parameter is related to the threshold value causing a deviation in the linearity of the voltage due to mass transfer limitations. Because of that, the change in the value of $n$ parameter indicated that 
limitations due to the mass transference took place. In Table 2, it can be that the $n$ parameter, and therefore the threshold current density at which the limitations took place, was lower when the nitrate concentration increased, indicating a direct relationship between the nitrate concentration and limitations caused by the mass transference. The mass transference problems could be related to the competition of the electrogenic microorganisms and denitrifiers for the same substrate. Higher substrate removal rates by denitrifiers could lead to a limited substrate availability for the electrogenic microorganisms, and consequently caused the lower electricity generation.

The modelling results suggested that the activation losses, kinetics limitation and internal resistance were very similar in all the cases, regarless the nitrate concentration experienced, discarding the hypothesis of inhibition of the electrogenic microorganisms by nitrate. On the other hand, it was found that the main limitation that ruled the MFC performance was the mass transfer limitations. 


\section{Conclusions}

The electrical performance of the studied MFC was maintained almost unaltered when the influent nitrate concentrations were below $0.9 \mathrm{mg} \mathrm{N}-\mathrm{NO}_{3} \mathrm{~L}^{-1}$. Over this value, reduction in the voltage exerted by the MFC. When the nitrate concentration was $3.4 \mathrm{mg} \mathrm{N}-\mathrm{NO}_{3} \mathrm{~L}^{-1}$, the reduction was approximately $9 \%$ and $22 \%$ with respect to the open circuit voltage and the maximum power density exerted, respectively.

The electrical performance was modelled using an empirical model based on the polarization curve. The activation losses, kinetics limitation and internal resistance remained unaltered regardless of the different nitrate concentrations fed to the MFC. However, mass transfer limitations occurred while feeding nitrate. The mass transfer limitations could be explained by the competence between the electrogenic microorganisms and denitrifiers for the same substrate. In this competence, the denitrifiers outcompete the electrogenic ones reducing the voltage exerted by the MFC.

\section{Acknowledgements}

The funding thorough Project POII10-0329-5194 (Junta de Comunidades de Castilla-La Mancha) is gratefully acknowledged. 


\section{References}

[1] Lobato J, Gonzalez del Campo A, Fernandez FJ, Canizares P, Rodrigo MA. Lagooning microbial fuel cells: A first approach by coupling electricity-producing microorganisms and algae. Applied Energy. 2013;110:220-6.

[2] Logan BE, Hamelers B, Rozendal R, Schröder U, Keller J, Freguia S, et al. Microbial fuel cells: Methodology and technology. Environmental Science and Technology. 2006;40:5181-92.

[3] Chaudhuri SK, Lovley DR. Electricity generation by direct oxidation of glucose in mediatorless microbial fuel cells. Nature Biotechnology. 2003;21:1229-32.

[4] Fernández de Dios MT, del Campo AG, Fernández FJ, Rodrigo M, Pazos M, Sanromán MT. Bacterial-fungal interactions enhance power generation in microbial fuel cells and drive dye decolourisation by an ex situ and in situ electro-Fenton process. Bioresource Technology. 2013;148:39-46.

[5] Gude VG. Wastewater treatment in microbial fuel cells - an overview. Journal of Cleaner Production. 2016;122:287-307.

[6] Fernandez FJ, Seco A, Ferrer J, Rodrigo MA. Use of neurofuzzy networks to improve wastewater flow-rate forecasting. Environmental Modelling and Software. 2009;24:686-93.

[7] Gude VG. Energy and water autarky of wastewater treatment and power generation systems. Renewable and Sustainable Energy Reviews. 2015;45:52-68.

[8] Bao R, Zhang S, Zhao L, Zhong L. Simultaneous sulfide removal, nitrification, and electricity generation in a microbial fuel cell equipped with an oxic cathode. Environmental Science and Pollution Research. 2017;24:5326-34.

[9] Slate AJ, Whitehead KA, Brownson DAC, Banks CE. Microbial fuel cells: An overview of current technology. Renewable \& Sustainable Energy Reviews. 2019;101:60-81.

[10] Fernandez FJ, Sanchez-Arias V, Villasenor J, Rodriguez L. Evaluation of carbon degradation during co-composting of exhausted grape marc with different biowastes. Chemosphere.

2008;73:670-7.

[11] Fernández FJ, Sánchez-Arias V, Rodríguez L, Villaseñor J. Feasibility of composting combinations of sewage sludge, olive mill waste and winery waste in a rotary drum reactor. Waste Management. 2010;30:1948-56.

[12] Fernández-Morales FJ, Villaseñor J, Infantes D. Modeling and monitoring of the acclimatization of conventional activated sludge to a biohydrogen producing culture by biokinetic control. International Journal of Hydrogen Energy. 2010;35:10927-33.

[13] Huang H, Cheng S, Yang J, Li C, Sun Y, Cen K. Effect of nitrate on electricity generation in single-chamber air cathode microbial fuel cells. Chemical Engineering Journal. 2018;337:66170.

[14] Lian J, Tian X, Li Z, Guo J, Guo Y, Yue L, et al. The effects of different electron donors and electron acceptors on perchlorate reduction and bioelectricity generation in a microbial fuel cell. International Journal of Hydrogen Energy. 2017;42:544-52.

[15] Sukkasem C, Xu S, Park S, Boonsawang P, Liu H. Effect of nitrate on the performance of single chamber air cathode microbial fuel cells. Water Research. 2008;42:4743-50.

[16] Yi T, Harper WF. The Effect of Nitrate and Sulfate on Mediator-Less Microbial Fuel Cells with High Internal Resistance. Water Environment Research. 2009;81:2320-8.

[17] Kashima H, Regan JM. Facultative Nitrate Reduction by Electrode-Respiring Geobacter metallireducens Biofilms as a Competitive Reaction to Electrode Reduction in a Bioelectrochemical System. Environmental Science \& Technology. 2015;49:3195-202.

[18] Kiely PD, Call DF, Yates MD, Regan JM, Logan BE. Anodic biofilms in microbial fuel cells harbor low numbers of higher-power-producing bacteria than abundant genera. Applied Microbiology And Biotechnology. 2010;88:371-80.

[19] Nastro RA, Jannelli N, Minutillo M, Guida M, Trifuoggi M, Andreassi L, et al. Performance evaluation of Microbial Fuel Cells fed by solid organic waste: parametric comparison between 
three generations. 8th International Conference on Applied Energy (Icae2016). 2017;105:11028.

[20] Lobato J, Canizares P, Jesus Fernandez F, Rodrigo MA. An evaluation of aerobic and anaerobic sludges as start-up material for microbial fuel cell systems. New Biotechnology. 2012;29:415-20.

[21] Gonzalez Del Campo A, Cañizares P, Lobato J, Rodrigo MA, Fernandez FJ. Electricity production by integration of acidogenic fermentation of fruit juice wastewater and fuel cells. International Journal of Hydrogen Energy. 2012;37:9028-37.

[22] Mateo S, Rodrigo M, Fonseca LP, Cañizares P, Fernandez-Morales FJ. Oxygen availability effect on the performance of air-breathing cathode microbial fuel cell. Biotechnology Progress. 2015.

[23] Gonzalez del Campo A, Lobato J, Cañizares P, Rodrigo MA, Fernandez Morales FJ. Shortterm effects of temperature and COD in a microbial fuel cell. Applied Energy. 2013;101:213-7. [24] de Lucas A, Rodriguez L, Villasenor J, Fernandez FJ. Fermentation of agro-food wastewaters by activated sludge. Water Research. 2007;41:1635-44.

[25] American Public Health Association., American Water Works Association., Water Pollution Control Federation., APHA., AWWA., APCF. Standard methods for the examination of water and wastewater. 14th ed. Washington, D.C.,,1989.

[26] De Lucas A, Rodríguez L, Villaseñor J, Fernández FJ. Denitrification potential of industrial wastewaters. Water Research. 2005;39:3715-26.

[27] Ebrahimi S, Morales FJF, Kleerebezem R, Heijnen JJ, van Loosdrecht MCM. High-rate acidophilic ferrous iron oxidation in a biofilm airlift reactor and the role of the carrier material. Biotechnology and Bioengineering. 2005;90:462-72.

[28] Su SG, Cheng HY, Zhu TT, Wang HC, Wang AJ. Kinetic competition between microbial anode respiration and nitrate respiration in a bioelectrochemical system. Bioelectrochemistry. 2018;123:241-7.

[29] Bolzonella D, Innocenti L, Pavan P, Cecchi F. Denitrification potential enhancement by addition of anaerobic fermentation products from the organic fraction of municipal solid waste. Water Science and Technology2001. p. 187-94.

[30] Jannelli N, Nastro RA, Cigolotti V, Minutillo M, Falcucci G. Low pH, high salinity: Too much for microbial fuel cells? Applied Energy. 2017;192:543-50.

[31] Krastev VK, Falcucci G. Evaluating the electrochemical and power performances of microbial fuel cells across physical scales: A novel numerical approach. International Journal of Hydrogen Energy. 2019;44:4468-75.

[32] Mateo S, Cañizares P, Rodrigo MA, Fernandez-Morales FJ. Driving force of the better performance of metal-doped carbonaceous anodes in microbial fuel cells. Applied Energy. 2018;225:52-9. 